\title{
Temporal Orientation as a Core Element of World Representation in Polish Deaf Adolescents
}

\author{
Joanna Kossewska \\ Human Development Support Psychology Unit, Pedagogical University of Cracow, Cracow, Poland
}

\begin{abstract}
Temporal orientation is one of the attributes of world representation understood as a system of knowledge comprising an individual's information and beliefs developing as the individual gains experience, which plays a regulative role in making choices, building attitudes towards the real world and solving problems. As deafness is a fundamental factor influencing individual experience and development, which effects all core psychological elements as the time perception (Kowalska \& Szelag, 2006) on the one hand up to attachment patters and communication process with significant others on the other (Thomson, Kennedy, \& Kuebli, 2011). Due to this facts, it was assumed that deafness might also influence the world representation in reference to its temporal characteristics. Two groups of adolescents (with and without hearing impairment) aged at 15 up to 19 years were tested individually with the Method "Map of My World" (Gurycka, 1994). As it was found the world representation of deaf adolescents was characterized by the presence of temporal elements representing present orientation with simultaneous lack of past references as in their typically developed peers and the lower evidence of future temporal elements $(F=13.416, p<0.001)$. It might be concluded that deafness is the core factor influencing the development of future time orienterion complexity.
\end{abstract}

Keywords: deafness, world representation, temporal orientation, temporal perspective, future goals

\section{Introduction}

Temporal orientation or perspective is one of the attributes of world representation understood as a system of knowledge comprising an individual's information and beliefs developing as the individual gains experience, which plays a regulative role in making choices, building attitudes towards the real world and solving problems (Gurycka, 1994). Temporal perspective is a fundamental process in both individual and societal functioning (Zimbardo \& Boyd, 1997; 2009). It is defined as a non-conscious process in which temporal categories (past, present, future) play a leading-connective role in the relationship between personal and social experiences. These categories help us to give meaning and order to everyday life events. Temporal cognitive frames are core background for encoding, storing, and recalling personal and societal events, as well as for building personal expectations, goals, and imaginative views. Individual time perspective is learned frame for many human cognitive processes as judgement, decision and actions, for example a more future-based time perspective could

\footnotetext{
*Acknowledgements: The author would like to express gratitude to Professor Philip Zimbardo for inspiration and constructive remarks. Research was presented during poster session at the First Conference on Time Perspective, Coimbra, Portugal, September 5-8, 2012 entitle as "Temporal orientation as the attribute of world representation in deaf adolescents".

Joanna Kossewska, Ph.D., assistant professor, Human Development Support Psychology Unit, Department of Psychology, Pedagogical University of Cracow, e-mail: joanna.kossewska@up.krakow.pl.
} 
help students study and progress to higher education (Zimbardo \& Boyd, 1999).

Temporal perspective is a well described construct in typical population, however, there is are only few studies related to disability specific situations (Brzezińska, Kaczan, \& Rycielska, 2010). Deafness is a factor influencing individual experience and development (Marschark, 1993) firstly due to the lack of specific audio stimulation resulting form specific brain formation as well as, secondly, the specific developmental family context because more than $90 \%$ of deaf children are born to hearing parents, and these children may not have received any usable language input during critical language acquisition periods. However, in reference to contemporary deafness model, it is understood rather as a cultural language minority or a personal trait then a disability (Lane, 1997). It might give a specific context for temporal perspective learning process in reference to future thinking and future goal orientation.

Due to developmental importance of temporal perspective, the following questions emerge: (1) What difference are found between the temporal representation of the deaf in comparison to their hearing peers; (2) What temporal categories are important for deaf adolescents and perceived as core elements of their world representation.

\section{Materials and Methods}

\section{Participants}

Adolescents aged at 15 up to 17 years from upper secondary schools in Cracow (south of Poland) of two groups (10 boys and 10 girls each) were tested. One group consisted of 20 deaf and hard-hearing adolescents from secondary segregated school for deaf and hard-hearing youth in Cracow. The control group consisted of secondary school students paired with the experimental group by age and gender.

\section{Method}

The testing method applied was the so-called "Map of My World", used to assess general cognitive structures of individuals. It allows not only to learn the perception of various constructs, but also to assess object categories that a person uses to construct their representation of the world. Cognitive representation of the world was described in categories proposed by A. Gurycka (1994), the central focus of the previous research was time orientation. The method had been checked via broad normalisation study that showed its high reliability and accuracy (Tarnowski \& Neff, 1997).

\section{Procedure}

Subjects were tested individually in an isolated room at the school settings of the schools they attend. Tests and assessments were carried out according to the instructions (Tarnowski \& Neff, 1997). Each subject was shown a set of signs and symbols and asked to use them to draw with the colour pencils his/her world vision on a clean white sheet of paper. Subjects were asked to include in their picture all significant objects, persons, ideas, objectives, and values, their own relation towards each of them and relations between the elements. The instruction was given to the deaf group in both mode of communication: the Polish language as well as PJM (Polish Sing language).

It should be mentioned here that "The Map of My World" is not a projective technique, i.e., the researcher does not analyse the result in order to learn about the unconscious in the subject. Subjects draw the world as they see it, and the analysis is only a systematic description of the drawing.

Maps were analysed in reference to differences in temporal categories content within the quantitative and qualitative perspective. 


\section{Results and Discussion}

The "Map of My World" method allows to apply qualitative as well as quantitative analytic techniques. Quantitative analysis of general categories proposed by A. Gurycka (1994) has been applied to present group differences in temporal orientation (see Table 1).

Table 1

Differences Between the Deaf and the Hearing in Reference to Temporal Categories

\begin{tabular}{lllllll}
\hline Variable & \multicolumn{3}{c}{ Deaf adolescents } & \multicolumn{2}{c}{ Hearing adolescents } & \multicolumn{2}{c}{ Variance analysis } \\
\hline & Mean & $S D$ & Mean & $S D$ & $F(d f=38)$ & $p$ \\
Temporal categories given at the world vision & 58.05 & 2.04 & 86.20 & 7.47 & 13.42 & 0.001 \\
\hline
\end{tabular}

The deaf adolescents presented significantly fewer temporal categories on their world representation than the hearing peers $(F=13.42, p<0.001)$, however, the inside group differenciation was lower. This means that deaf individuals are more similar to each other within the deaf group in their world vision temporal concentration, however, the deaf group is in general less concentrated on temporal objects and categories than the hearing one. Qualitative analysis showed that temporal categories by the deaf presented in their maps of world representation were usually related to present real objects, such as school (the building), peer (colleagues, friends) and family relationships (family members), and dating (boyfriend/girlfriend). However, the world vision of hearing adolescents included significantly more objects related to the temporal categories which were connected with both vocational (studying, voluntary work, professional experience), as well as social (marriage, procreative family relationships), and future personal goals (developing skills, learning new skills, increasing personal resources, and dealing with problems).

This result is very informative when applied to the content of the subjective world representation. On the one hand, the human actions are usually motivated by the representational object keeping one mind then by the real object observed. On the other hand, the representation is constructed as the mental equivalent of real, fictional, or hypothetical objects, by creating a complex mind construct. The process consists of coding sensory data in language categories, as the result of which, sensory data is translated into mind data. Intermediary role is ascribed to the speech in this process. Thus in connection to difficulties with developing the verbal language, the deaf youth has limited possibilities in constructing future temporal categories in their minds, which would surpass current sensory experience. Presented findings are coherent with research done in Poland in the late eighties by Kaiser-Grodecka and Cieszynska (1991). The authors found that deaf adolescents aged 12-15 faced two level difficulties in time sequencing events at the timeline. Primary temporal ordering is related to both personal individual past experiences coded in episodic memory and goals and aspirations anticipated by the process of episodic future thinking. The primary time ordering is the fundamental base for historical secondary time ordering process development, which is connected with semantic memory. Both levels of temporal ordering processes seem to be delayed in deaf adolescents.

The presented results may stem from the fact that the deaf group was made up of hearing parents' deaf children. Due to the fact that $90 \%$ of deaf children are born to hearing parents, they may not have received any usable language input during critical language acquisition periods of brain development. Lacking language input during a child's earliest years and the underdevelopment of a formal language system can result in an adult without fluency or competence in any language, including sign language (Sacks, 1989). Hearing family usually creates the low-stimulating developmental environment. Possession of a language system is necessary 
to facilitate abstract thinking, mature personality development and future goal orientation. Without such a system, some deaf people may lack the ability to think abstractly or to generalize concepts. The development of future time orientation might be also limited by the low level of verbal communication skills, to the result that an average deaf adult reads English at a fourth grade level (Haskins, 2000).

Deafness has historically been viewed as a sensory impairment associated with disabilities. On the other hand, views on deafness as a culture have recently emerged and consider deafness as a personal trait, not as disability (Lane, 1997). Deaf people belong to Deaf culture, which according to Berry's (1990) definition, refers to the widely shared ideals, values, formation and uses of categories, assumptions about life, and goal-directed activities that become unconsciously or subconsciously accepted as "right" and "correct" by Deaf $^{1}$ people who identify themselves as members of a sign language minority group.

Within deaf culture, the time orientation is polychromatic and more focused on the past or the present in relation to the hearing one (Mindess, 1999, as cited in Slife, 2007). Polychromatic orientation means more contextual orientation towards time that takes in multiple reference points from the past, present, and future. Stories that are told are carriers of history, ways of repeating and reformulating the past for the present (Padden \& Humphries, 1988). There is awareness of time and schedules within the deaf community, but there is a difference in the degree of importance of the schedule in comparison to the hearing one. People in the field of deafness or the deaf community often refer to "deaf time": Meaning that deaf people do not start events "on time", which may be because deaf people put more emphasis on people and relationships than on the clock. If a meeting is scheduled to start at 8:00, people may arrive and greet each other at that time, but often the formal meeting does not start until 8:30 (Padden, 1980). Comprehensive studies of deaf culture were done in an American minority, so it is interesting to find out if the temporal orientation conclusions are universal and present in the Polish deaf. The results of presented survey seem to confirm that deafness is related to lower level of future temporal perspective (orientation).

Specific cognitive abilities in deafness (Stachyra, 2000) might affect temporal perspective as an element of the world representation. The youth also make plans for the future, think and dream about becoming self-independent, which they reveal by expressing their own expectations and desires. But limitations in the intellectual sphere, lack of the ability of abstract thinking do not enable to perceive significant connection between one's own action and its effects. These restrictions do not allow to predict the course of events happening independently of the subject. It hinders the possibility of influencing the course of events and one's own fate, and taking intended and intentional actions. As a consequence, the youth with deafness might have difficulties in defining states which do not exist yet, or in creating realistic plans for the future. They also often cannot evaluate their conduct skills appropriately. They assess various social situations from the perspective of one's own point of view, not being able to look at the given situations from the perspective of others. This is due to limited theory of mind ability (Peterson, Wellman, \& Liu, 2005).

Polish deaf adolescents usually attend segregated schools and live in a dormitory outside their family. Social life and realisation of interests have moved out of the family. For deaf and hard-hearing youths, institutions of the real world perform complex functions: socialisation, education, and upbringing. Institutions create a controlled environment where young people may develop and satisfy their needs. They give them a

\footnotetext{
${ }^{1}$ A lower-case letter $d$ usually stands for medical diagnoses of hearing impairment (deaf) and an upper-case letter $D$ stands for linguistic and cultural minority (Deaf).
} 
chance to fulfill the need of influence which is very important in the development of a mature, responsible personality. Their concentration on the present time perspective may limit the range of deaf adolescents' judgements, decisions and actions. Only few deaf youths pointed out the prolong education and profession as important values within the future context, while according to Zimbardo and Boyd (1999), a more future-based time perspective could help students study and progress to higher education. Deaf and hard-hearing adolescents develop in relatively less secure environments due to the lack of common family communicative mode as well as insecure childhood attachment pattern (Thomson, Kennedy, \& Kuebli, 2011), it may be followed by present oriented behavioural strategies, which reflect an orientation towards immediate outcomes and little concern for future consequences.

Many studies found more mental health problems among hard of hearing and deaf adults than in the general population. It has been proven that the greater the degree of hearing loss, the more mental health problems are experienced (e.g., Pollard, 1998; Tambs, 2004). The higher amount of mental health disorders, such as depression, might be related to the low level of future time perspective in deaf people because this sort of time orientation is usually related to low subjective well-being and a higher level of depression in general population as well (Coudin \& Lima, 2011). The mental health problems might be more complex and serious when there are common impacts of many developmental factors, such as lack of safety, low level of communication, which is disfulfillment of psychological personal needs.

\section{Conclusion}

The deaf and hard-hearing Polish adolescents presented significantly fewer amount of temporal categories on their world representation than the hearing peers did. These temporal categories are usually related to present real objects as school, peer and family relationships, and dating. However, the world vision by hearing adolescents includes more future time perspective which is related to both vocational, as well as social and personal goals. This construct of time perspective might be related to both deaf culture characteristic or some developmental factors as well (lack of common communication mode within the family context, or boarding segregated school setting).

\section{References}

Berry, J. (1990). Psychology of acculturation. In R. W. Brislin (Ed.), Applied cross-cultural psychology (pp. 232-253). Newbury Park, C.A.: Sage Publications.

Brzezińska, A., Kaczan, R., \& Rycielska. (2010). Czas, plany, cele: Perspektywa temporalna osób z ograniczeniami sprawności. Warszawa: Scholar.

Coudin, G., \& Lima, M. L. (2011). Being well as time goes by: Future time perspective and well-being. International Journal of Psychology and Psychological Therapy, 11(2), 219-232.

Gurycka, A. (1994). Reprezentacja świata w umysłach młodzieży-geneza. Warszawa: Pracownia Wydawnictwa PTP.

Haskins, B. M. D. (2000). Serving and assessing deaf patients: Implications for psychiatry. Psychiatric Times, XVII(12).

Kaiser-Grodecka, I., \& Cieszynska, J. (1991). The understanding of time by deaf pupils. In D. S. Martin (Ed.), Advances in cognition, education and deafness (pp. 201-204). Washington: Gallaudet University Press.

Kowalska, J., \& Szelag, E. (2006). The effect of congenital deafness on duration judgment. Journal of Child Psychology and Psychiatry, 47(9), 946-953.

Lane, H. (1997). Construction of deafness. In L. Davis (Ed.), The disability studies reader (pp. 153-171). New York: Routledge.

Marschark, M. (1993). Origins and interactions in social, cognitive, and language development in deaf children. In M. Marschark, \& M. D. Clark (Eds.), Psychological perspectives on deafness (pp. 7-26). Hillsdale, N.J.: Lawrence Erlbaum Associates. 
Padden, C. (1980). The deaf community and the culture of deaf people. In C. Baker, \& R. Battison (Eds.), Sign language and the deaf community (pp. 89-103). Silver Spring, M.D.: Linstok Press.

Padden, C., \& Humphries, T. (1988). Deaf in America, voices from a culture. Cambridge, M.A.: Harvard University Press.

Peterson, C. C., Wellman, H. M., \& Liu, D. (2005). Steps in theory of mind development for children with autism and deafness. Child Development, 76, 502-517.

Pollard, R. Q. (1998). Psychopathology. In M. Marschark, \& D. Clark (Eds.), Psychological perspective on deafness (Vol. 2, pp. 171-197). Mahwah, N.J.: Lawrence Erlbaum, Inc..

Sacks, O. (1989). Seeing voices: A journey into the world of the deaf. Berkeley, C.A.: University of California Press.

Slife, N. (2007). Exploring leadership among deaf college students: A comparative study at a population serving institution and predominantly hearing institutions. University of Maryland.

Stachyra, J. (2001). Zdolności poznawcze i możliwości umysłowe uczniów z uszkodzonym słuchem. Lublin: UMCS.

Tambs, K. (2004). Moderate effects of hearing loss on mental health and subjective well-being: Results from the Nord-Trøndelag hearing loss study. Psychosomatic Medicine, 66, 776-782.

Tarnowski, A., \& Neff, T. (1997). Analiza Światopogladu Człowieka za pomoca Mapy Mojego Świata. Warszawa: Wydział Psychologii UW.

Thomson, N. R., Kennedy, E. A., \& Kuebli, J. E. (2011). Attachment formation between deaf infants and their primary caregivers: Is being deaf a risk factor for insecure attachment? In D. H. Zand, \& K. J. Pierce (Eds.), Resilience in deaf children: Adaptation through emerging adulthood (pp. 27-64). Springer.

Zimbardo, P., \& Boyd, J. (1999). Putting time in perspective: A valid, reliable individual-difference metric. The Journal of Personality and Social Psychology, 77, 1271-1288.

Zimbardo, P., \& Boyds J. (2009). The Time paradox: The new psychology of time that will change your life. New York: Free Press. 